\title{
Hydrogen effect on the properties of sapphire
}

Radion N. Mogilevsky, Liudmila G. Sharafutdinova, Sergiy Nedilko, Valeriy Gavrilov, Dmitriy Verbilo, et al.

Radion N. Mogilevsky, Liudmila G. Sharafutdinova, Sergiy Nedilko, Valeriy Gavrilov, Dmitriy Verbilo, Scott D. Mittl, "Hydrogen effect on the properties of sapphire," Proc. SPIE 7302, Window and Dome Technologies and Materials XI, 730204 (27 April 2009); doi: 10.1117/12.818148

SPIE Event: SPIE Defense, Security, and Sensing, 2009, Orlando, Florida, United States 


\title{
Hydrogen effect on the properties of sapphire
}

\author{
Radion N. Mogilevsky ${ }^{1}$, Liudmila G. Sharafutdinova ${ }^{1}$, Sergiy Nedilko ${ }^{2}$, Valeriy Gavrilov ${ }^{3}$, Dmitriy \\ Verbilo ${ }^{4}$, Scott D. Mittl ${ }^{5}$ \\ 1 Emerging Material Technologies, Inc 1491 Littlefield Court, Lake Forest, IL 60045, USA2 \\ 2 Kyiv National Taras Shevchenko University, 64, Volodymyrska Str. 01033, Kyiv, Ukraine \\ 3 JSC "Technocrystal", 1, Timiriazevskaya Stret, 01014, Kyiv, Ukraine. \\ 4 Frantsevich Institute for Problems of Materials Science, 3 Krzizanovskogo St. Kiev, Ukraine \\ 5 Insaco, Inc, 1365 Canary Road, Quakertown, PA, 18951 USA
}

\begin{abstract}
Sapphire is a widely used material for optical, electronic and semiconductor applications due to its excellent optical properties and very high durability. Optical and mechanical properties of sapphire depend on many factors such as the starting materials that are used to grow crystals, methods to grow sapphire crystals, etc. Demand for highest purity and quality of sapphire crystals increased ten fold for the last several years due to new applications for this material.

In this work we studied the effect of starting materials and crystal growth methods on the optical and mechanical properties of sapphire, especially concentrating on the effect of hydrogen on the properties of sapphire.

It was found that the infrared (IR) absorption which is traditionally used to measure the hydrogen content in sapphire crystals cannot be reliably used and the data obtained by this method provides a much lower hydrogen concentration than actual. We have shown for the first time that Nuclear Magnetic Resonance techniques can be successfully used to determine hydrogen concentration in sapphire crystals.

We have shown that hydrogen concentration in sapphire can reach thousands of ppm if these crystals are grown from Verneuil starting material or aluminum oxide powder. Alternatively, the hydrogen concentration is very low if sapphire crystals are grown from High Purity Densified Alumina $\left(\mathrm{HPDA}^{\circledR}\right.$ ) as a starting material. HPDA ${ }^{\circledR}$ is produced by EMT, Inc through their proprietary patented technology.
\end{abstract}

It was found that optical and mechanical properties of sapphire crystals grown using EMT HPDA ${ }^{\circledR}$ starting material are much better than those sapphire crystals grown using a starting material of Verneuil crystals or aluminum oxide powder.

Keywords: sapphire crystals, transmission, absorption, flexure strength, impurities, hydrogen, Nuclear Magnetic Resonance,

\section{Introduction}

\section{Sapphire market}

Un-doped sapphire or single crystal aluminum oxide has long been known to be an excellent material for optical and laser application [1-3]. Recently, sapphire found its application in nuclei technology and X-ray radiometry and doped sapphire is a likely material to be used as optical storage media [4]. Demand for un- doped sapphire increased tens fold recently due to its application in production of blue LED devices. In this application, sapphire is the best and the most economical substrate to deposit GaN based compound, the material that produces blue light in LED devices [5]. Another rapidly growing application for sapphire crystals is "silicon on 
sapphire" to be used in integrated circuit manufacturing for mobile handsets [6]. Sapphire also is a prominent material to be used as transparent armor [7] due to its high durability and strength. Estimates have shown that sapphire industry will grow from a "cottage industry" in 2000 to a $\$ 400$ million industry by 2012[8].

\section{Starting Materials}

Common knowledge has been that higher purity will yield greater and more consistent properties of sapphire crystals. The best way to control the purity of sapphire had been to control the purity of the starting material. However, the control of the starting or "raw" material used to make sapphire has been limited. Traditionally, the raw material of choice has been the "by-product" of the "flame fusion" or Verneuil process typically called "crackles" [9]. This process involves oxygen-hydrogen flame, causing the possibility of contamination by hydrogen in grown crystals.

An alternative starting material has been the aluminum oxide powder itself. However, while starting with a powder yields a reasonable quality crystal, the effort and reasonably poor size of the crystals make this process un-economical. Also, it is well known that aluminum oxide powder is a very hydroscopic material and is possible to absorb a very large quantity of water.

Emerging Material Technologies, Inc (EMT) has developed and patented a method for the preparation of raw material in which alumina powder goes through high temperature $\left(>10,000{ }^{\circ} \mathrm{C}\right.$ ) plasma in which it melts with the following crystallization into a densified product. In this process, no hydrogen is used and the traces of water that might come from the starting aluminum oxide powder is simply vaporized together with other impurities. This allows for production of High Purity Densified Alumina (EMT HPDA ${ }^{\circledR}$ ) with the purity of $>99.999 \%$ and free of hydrogen impurities.

\section{Measurement Techniques}

Several analytical techniques have been developed in the past that are able to measure impurities level in sapphire to ppm limits $[10,11]$. The most commonly used method is Glow Discharge Mass Spectrometry (GDMS) with resolution of up to $0.01 \mathrm{ppm}$ for most elements of periodic table, excluding certain elements such as: hydrogen, carbon, and nitrogen. Hydrogen concentration has been measured using traditional IR absorption methods [12]. This method works well for materials such as fused silica. Hydrogen concentration in fused silica ranges from several ppm to several thousand ppm which can easily and reliably be detected by IR absorption method.

One would expect that Verneuil grown sapphire would have very high hydrogen concentration due to the growth process that evolves hydrogen-oxygen flame. But surprisingly it was reported by many researchers that hydrogen concentration in Verneuil grown sapphire measured by method of IR absorption reaches only couple of ppm $[13,14]$. The same low level of hydrogen concentration was also found in the naturally formed corundum crystals if measured using the same method of IR absorption [15].

The Nuclear Magnetic Resonance (NMR) method has been known for a long time but was only recently successfully applied to measure low concentration of hydrogen in nominally anhydrous minerals [16]. We applied the NMR method for the first time, together with the traditional IR absorption method to sapphire crystals grown by different growth techniques and utilizing different starting materials \{17].

\section{Test Plan}

Sapphire samples for measurements were produced using sapphire crystals grown by Czchokraski process (Cz), Edge Defined Method (EFG), Kyropoulos (Kyr) and Heat Exchange Method (HEM) utilizing different raw materials: Verneuil crystals (Ver), alumina powder and High 
Purity Densified Alumina (EMT HPDA $\left.{ }^{\circledR}\right)$.

The level of impurities in all samples was determined using the GDMS and NMR methods. Transmission and absorption were measured in all samples over the range of $200 \mathrm{~nm}$ up to 7000 $\mathrm{nm}$ on the polished samples with the thickness of $10 \mathrm{~mm}$ [17]

Photoluminescence $(\mathrm{PL})$ spectra were measured at room and $77 \mathrm{~K}$ temperatures and were excited using radiation of various laser sources with excitation wavelengths of 473 and $532 \mathrm{~nm}$. The density of radiation power was in the limits of $0.05-0.4 \mathrm{Wt} / \mathrm{cm}^{2}$.

Flexure strength measurements were done at room temperature for sapphire crystals using 4point bending as it described in [18].

It was found that hydrogen plays a significant role in controlling optical and mechanical properties of sapphire: the lower hydrogen content the better all characteristics of sapphire crystals.

\section{Results and discussions}

\section{Impurity measurement results}

Results of impurity concentration measurements, including hydrogen, are presented in Table 1. A detailed description of the NMR methods and hydrogen concentration measurements are presented in our previous paper [17]

As can be seen from this table starting materials and grown crystals demonstrate very low impurities concentration for all elements except hydrogen. Total impurity concentration not considering hydrogen measured only couple of ppm in all measured samples. In contrast, hydrogen concentration in Verneuil crystals, alumina powder and corresponding sapphire crystals grown from these starting materials show very large hydrogen concentration reaching thousands of ppm when measured using the NMR method. One can see that hydrogen concentration measured on the same samples but using method of IR absorption show very low hydrogen concentration. This is in agreement with previously reported results for hydrogen content in sapphire crystals measured by the same method of IR absorption [13-15]. The NMR method should be considered as a direct method to measure the quantity of hydrogen protons regardless of the position that the hydrogen atom can occupy in aluminum oxide lattice. In contrast, the IR absorption method can be considered as an indirect method to measure hydrogen content since it only measures the concentration of $\mathrm{OH}$ bonds, from which the hydrogen content is calculated. There are other ways, such as interstitial sites, complicated point defects, etc which may be an important means of incorporating the hydrogen in sapphire. IR absorption is probably not an appropriate method for aluminum oxide (sapphire) to determine real hydrogen concentration and more reliable results are obtained using the NMR method or any other direct methods. Similar large discrepancies were observed [19] during measurements of hydrogen content in crystalline quartz using IR absorption method and ion beam spectrochemical analyzer. They discovered that hydrogen concentration was orders of magnitude higher if measured by the direct method of ion beam spectro chemical analyzer compared to the indirect IR absorption method.

The Hydrogen concentration in EMT HPDA ${ }^{\circledR}$ starting material is orders of magnitude lower than the alumina powder and Verneuil starting materials (see Table 1), using the NMR measurement technique. Similarly, the crystals grown from EMT HPDA ${ }^{\circledR}$ starting material also have significantly lower hydrogen concentration. 
Table 1.

Impurity content of the sapphire samples measured by GDMS, IR and NMR methods

\begin{tabular}{|c|c|c|c|c|c|c|c|c|c|}
\hline Sample & $\begin{array}{l}\text { Alumina } \\
\text { powder }\end{array}$ & $\begin{array}{l}\text { Verneuil } \\
\text { crystals }\end{array}$ & $\begin{array}{l}\text { EMT } \\
\text { HPDA }^{\circledR}\end{array}$ & $\begin{array}{l}\text { CZ } \\
\text { Verneuil }\end{array}$ & $\begin{array}{l}\mathrm{CZ} \\
\text { HPDA }^{\circledR}\end{array}$ & $\begin{array}{l}\text { Kyr } \\
\text { Verneuil }\end{array}$ & $\begin{array}{l}\text { Kyr } \\
\text { HPDA }^{\circledR}\end{array}$ & $\begin{array}{l}\text { HEM } \\
\text { Verneuil }\end{array}$ & $\begin{array}{l}\text { HEM } \\
\text { HPDA }^{\circledR}\end{array}$ \\
\hline & ppm & ppm & ppm & ppm & ppm & ppm & ppm & ppm & ppm \\
\hline $\mathrm{Na}$ & 4 & $<0.05$ & $<0.05$ & 1 & $<0.05$ & $<0.05$ & $<0.05$ & $<0.05$ & $<0.05$ \\
\hline Mg & 2 & 0.1 & $<0.05$ & 0.5 & 0.2 & 0.1 & $<0.05$ & 0.1 & $<0.05$ \\
\hline Si & 5 & $<0.5$ & $<0.5$ & $<0.5$ & $<0.5$ & $<0.5$ & $<0.5$ & $<0.5$ & $<0.5$ \\
\hline K & 2 & 0.5 & 0.1 & 0.5 & $<0.05$ & $<0.05$ & $<0.05$ & $<0.05$ & $<0.05$ \\
\hline $\mathrm{Ca}$ & 3 & 0.1 & 0.2 & 0.9 & 0.6 & 0.6 & 0.5 & 0.8 & 0.6 \\
\hline $\mathrm{Ti}$ & $<0.1$ & $<0.1$ & $<0.1$ & $<0.1$ & $<0.1$ & $<0.1$ & $<0.1$ & $<0.1$ & $<0.1$ \\
\hline $\mathrm{Cr}$ & $<0.1$ & $<0.04$ & $<0.04$ & $<0.04$ & 0.7 & $<0.04$ & $<0.04$ & $<0.04$ & $<0.04$ \\
\hline Mn & 0.1 & $<0.05$ & $<0.05$ & 0.07 & $<0.05$ & $<0.05$ & $<0.05$ & $<0.05$ & $<0.05$ \\
\hline $\mathrm{Fe}$ & 0.1 & 0.02 & 0.2 & 1 & 2 & 1 & 0.09 & 1 & 0.02 \\
\hline Co & 0.1 & $<0.05$ & $<0.05$ & $<0.05$ & $<0.05$ & $<0.05$ & $<0.05$ & $<0.05$ & $<0.05$ \\
\hline $\mathrm{Ni}$ & 0.2 & 0.2 & $<0.1$ & 0.5 & 0.3 & 0.2 & $<0.1$ & 0.3 & $<0.1$ \\
\hline $\mathrm{Cu}$ & 0.05 & 0.1 & 0.1 & 1 & 0.2 & 1 & 0.3 & 1 & 0.3 \\
\hline Zn & 0.4 & 0.3 & $<0.2$ & 1 & 0.9 & $<0.2$ & $<0.2$ & 0.7 & 0.5 \\
\hline Total & 16.9 & 1.5 & 0.6 & 6.7 & 4.9 & 2.9 & 0.89 & 3.9 & 1.42 \\
\hline $\begin{array}{l}\mathrm{H}_{2} \text { by } \\
\text { IR }\end{array}$ & N/A & 2.3 & N/A & $<0.2$ & 0.3 & $<0.2$ & $<0.2$ & 12 & $<0.2$ \\
\hline $\begin{array}{l}\mathrm{H}_{2} \text { by } \\
\text { NMR }\end{array}$ & 97000 & 1100 & 23 & 2560 & 243 & 635 & 355 & 807 & 410 \\
\hline
\end{tabular}

\section{Optical properties measurement results}

IR transmission was measured on the highly polished samples with thickness of $10 \mathrm{~mm}$ in range of $2000-7000 \mathrm{~nm}$.

As can be seen from Fig. 1 there is a significant variation in transmission for sapphire samples cut from different parts of the crystal boule if the starting material is crackles produced by Verneuil method. This variation in transmission can reach up to $10 \%-20 \%$ especially in far infrared range (Fig. 2 B), which can be problematic for the end use application.

In contrast, transmission for sapphire samples grown by the same method but grown using EMT HPDA $^{\circledR}$ starting material show very high (up to $96 \%$ see Fig. 1 ) transmission and very high uniformity all over the crystal (Fig.2 A). Similar observations were made in all groups of crystals grown by different methods.

Sapphire crystals grown from Verneuil starting material or aluminum oxide powder demonstrate very significant variation in transmission all over the crystal. Crystals grown using EMT HPDA ${ }^{\circledR}$ starting material exhibit no observed variation. Additionally, crystals grown from EMT HPDA ${ }^{\circledR}$ starting material always demonstrated higher transmission compared to crystals grown utilizing Verneuil crackles or alumina powder.

The precise physical mechanism by which absorption in IR range occurs is not completely 
understood. It is known [20] that impurities might produce absorption in sapphire crystals leading to decrease in transmission in IR range. Comparing trace element concentrations in sapphire

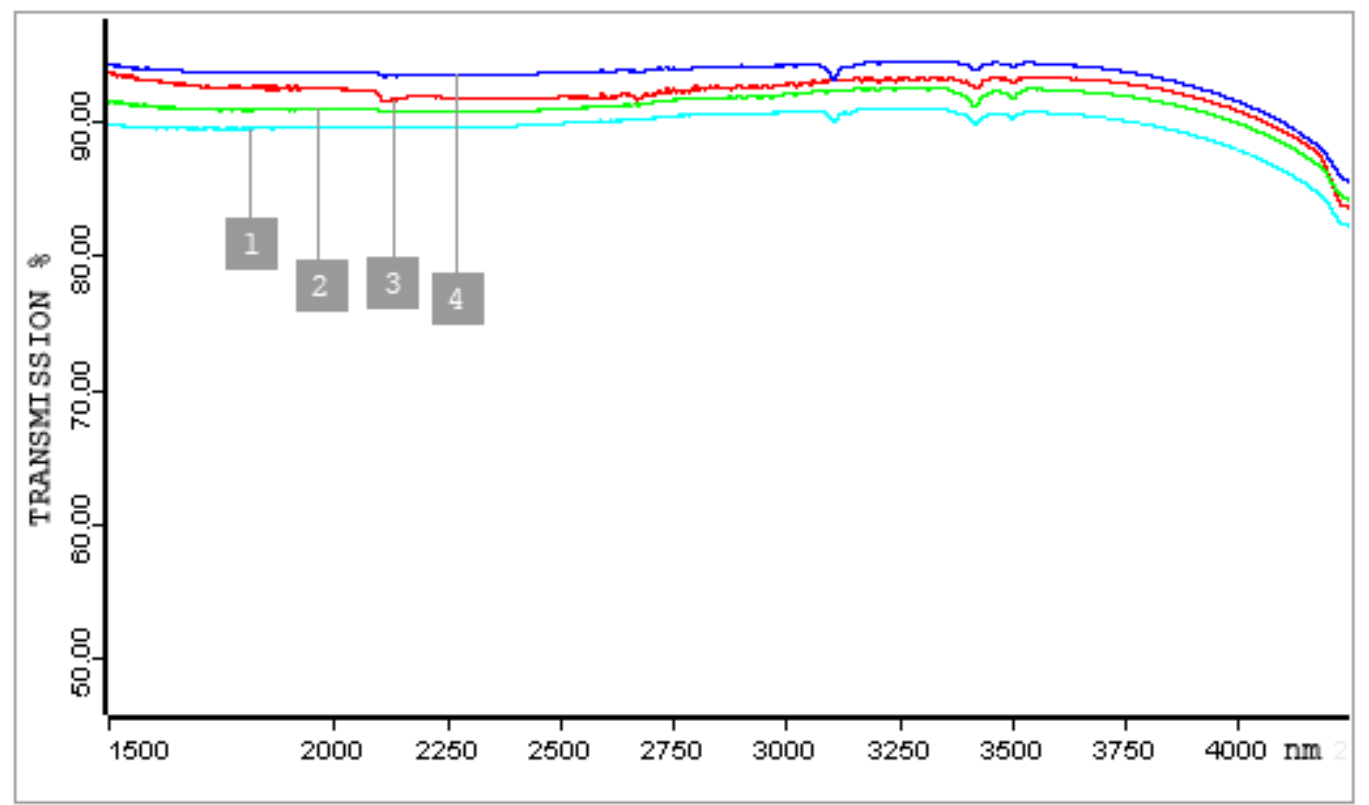

Fig.1 IR transmission sapphire crystals grown by CZ method $1,2,3$ Verneuil starting material, samples cut from different parts of the crystal, 4 - EMT HPDA ${ }^{\circledR}$ starting material
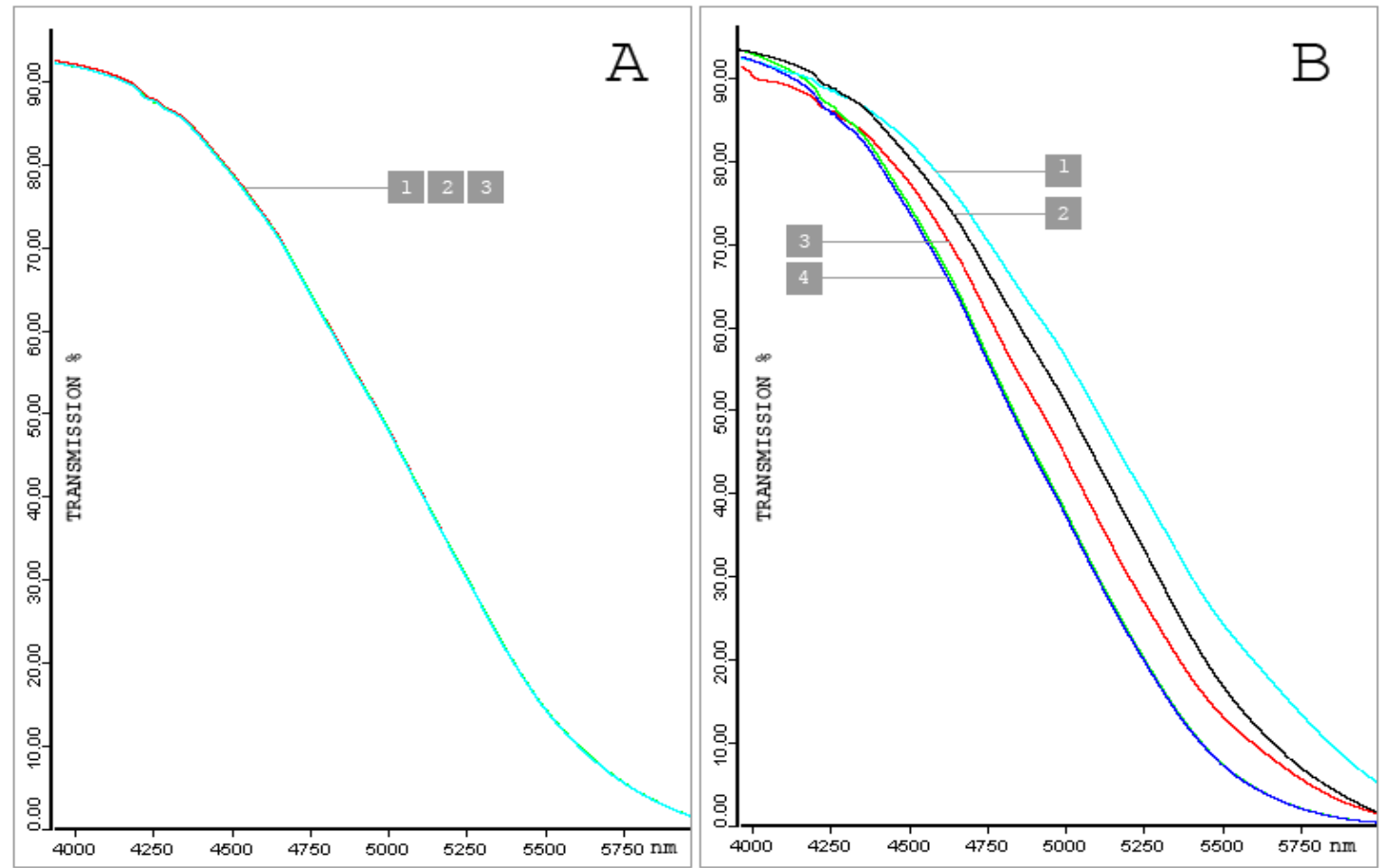

Fig. 2 IR transmission of sapphire crystals grown by Kyropoulos method 
A - EMT HPDA ${ }^{\circledR}$ starting material, B - Verneuil starting material

1, 2, 4 - samples cut from different parts of the crystal

3- Transmission of crystal produced by Verneuil process

crystals grown by different methods and utilizing different starting materials (Table 1 ) one might conclude that there is only one significant difference in impurity concentration- hydrogen concentration measured by NMR method. The difference in hydrogen concentration in sapphire crystals and starting materials can reach orders of magnitude. The lowest hydrogen concentration is in EMT HPDA ${ }^{\circledR}$ starting material (around 20-30 ppm) and sapphire crystals grown from EMT HPDA $^{\circledR}$ starting material. In Verneuil crystals and sapphire crystals grown from Verneuil starting material hydrogen concentration is reaching thousands of ppm. It is unclear how hydrogen might affect the transmission properties of sapphire and more investigation is required.

We also studied the UV transmission (from $200 \mathrm{~nm}$ ) in all selected samples (fig 3). It's known [21] that absorption in UV range can be caused by impurities_and structural defects. As can be seen from the transmission data there is not a significant absorption in any of the samples regardless of starting material, confirming that the impurity level (except hydrogen) is very low in all samples. However, the transmission in sapphire crystals grown from EMT HPDA ${ }^{\circledR}$ starting material is higher and more uniform than from crystals grown from Verneuil crackles or alumina powder.

Once again, we would like to emphasize that only hydrogen concentration is significantly different in these groups of crystals.

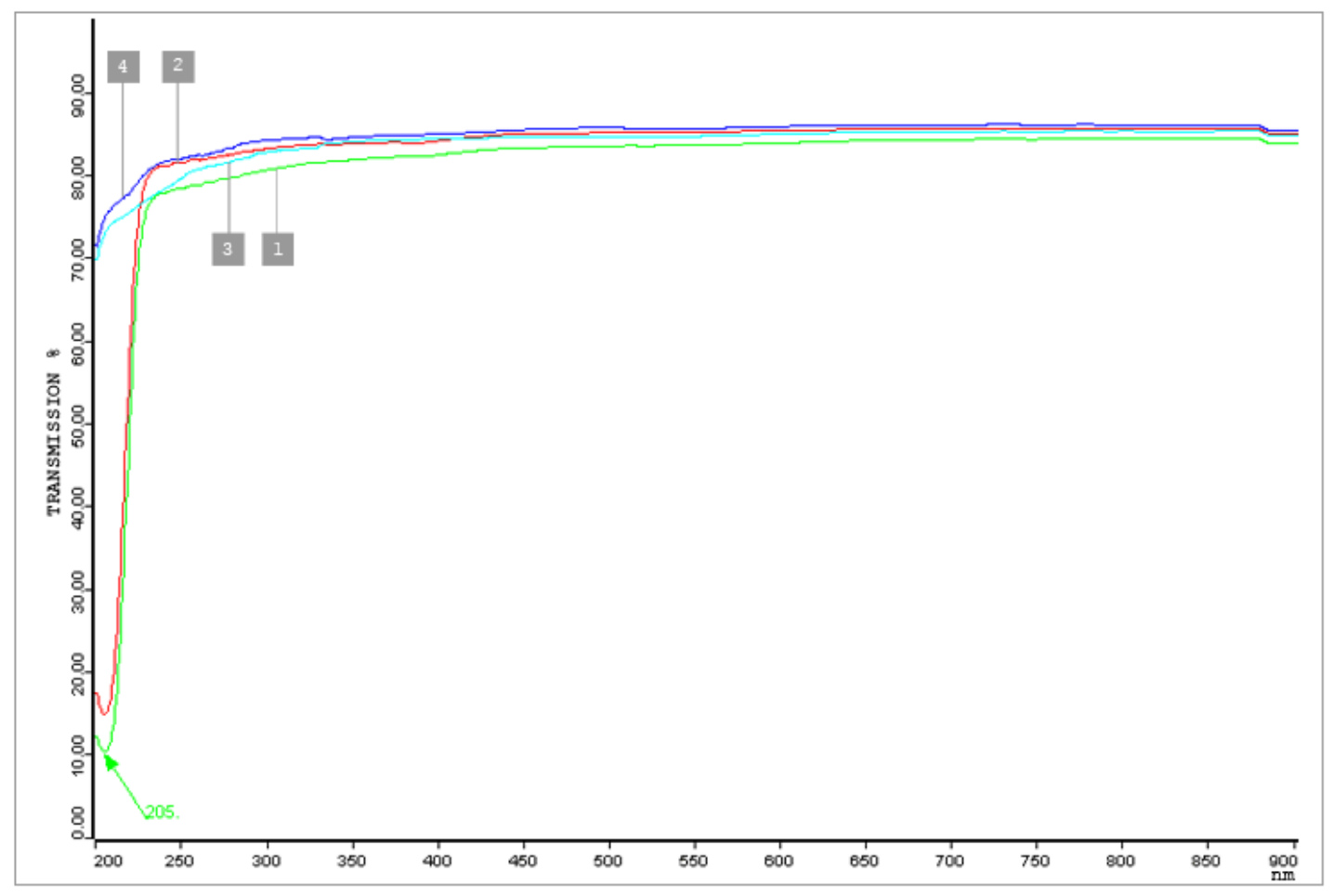

Fig. 3 UV transmission sapphire crystals grown by $\mathrm{Cz}$ method

1, 2, 3 Vernuil starting material, samples cut from different parts of the crystal 4- EMT HPDA ${ }^{\circledR}$ starting material 


\section{Luminescence properties measurement results}

The room temperature photoluminescence (PL) spectra of the studied samples are located in 600 - $850 \mathrm{~nm}$ wavelengths interval with two peaks if exciting at $\lambda_{\mathrm{ex}}=473$ and $532 \mathrm{~nm}$ (Fig. 4).Detailed description of samples preparation and experimental procedure are given in our previous paper [22] The red wide band (RWB) with the maximum at $\lambda_{\mathrm{m}} \approx 725 \mathrm{~nm}$ is the most intense (RWI integral intensity of this band) at these excitations. Besides mentioned wide band, a narrow line is observed at $\lambda_{\mathrm{m}} \sim 694 \mathrm{~nm}$ for the majority of samples. We concluded that observed narrow line is caused by ${ }^{2} \mathrm{E} \rightarrow{ }^{4} \mathrm{~A}_{2}$ radiation transition in $\mathrm{Cr}^{3+}$ ions that replace $\mathrm{Al}^{3+}$ ions in sapphire lattice [22].

The origin of the RWB emission is under the question. The RWI intensity of RWB depends on growth methods and starting materials. RWB intensity is lower for crystals grown by low temperature gradient methods such as Kyropoulos and HEM compare to large temperature gradient methods such as $\mathrm{Cz}$ and EFG. But for any particular method, the lowest value of RWB have been found out in the crystals grown using EMT HPDA ${ }^{\circledR}$ materials (Fig 5). The only significant difference between different starting materials is hydrogen concentration (table 1). There is not sufficient information to discuss in detail the physical mechanisms of hydrogen influence on PL properties of un doped sapphire crystals as the nature of RWB luminescence is not clarified yet. There is definite correlation between concentration of hydrogen and content of anionic vacancies which reveal in increasing of PL intensity of $F$ and $F_{2}$ color centers in crystals containing high level of hydrogen, but these observations are insufficient. However, hydrogen definitely plays significant role in RWB luminescence.

This type of luminescence was observed in LED devices, reducing efficiency of such devices [23, 24] and probably could be significantly or completely eliminated in sapphire substrates do not have hydrogen in their structure.

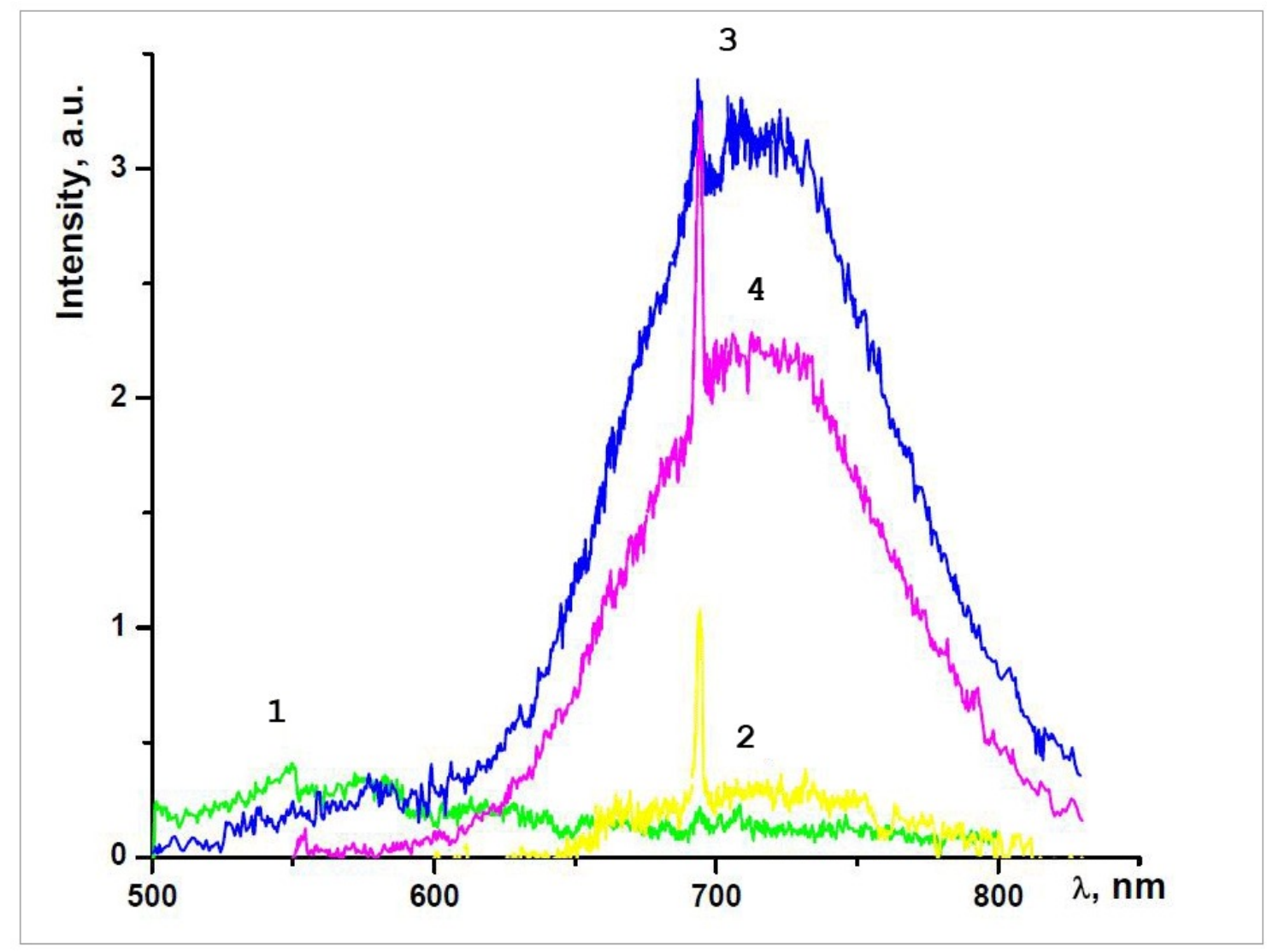


Fig. 4 Room temperature PL spectra sapphire crystals grown by Kyropoulos method 1 -EMT HPDA ${ }^{\circledR}$ starting material, 2- sapphire crystal grown from EMT HPDA ${ }^{\circledR}$ starting material 3- Verneuil starting material, 4- sapphire crystal grown from Verneuil starting material $\lambda_{\mathrm{ex}}=473 \mathrm{~nm}$

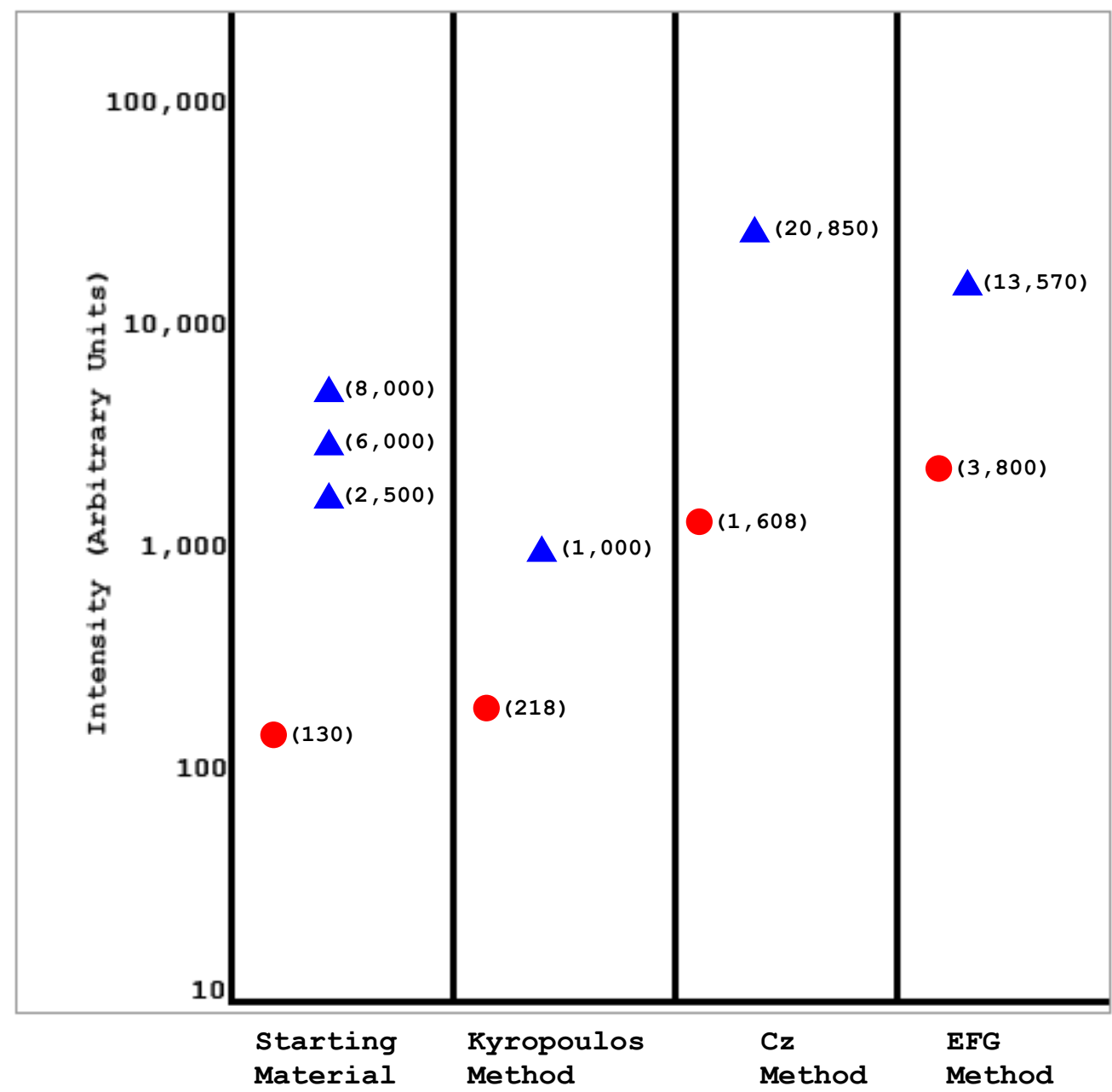

Fig. 5. Dependence of Red luminescence on starting materials and methods to grow sapphire crystals

EMT HPDA ${ }^{\circledR}$ starting material

- Verneuil starting material

Mechanical properties measurement results

Room temperature flexure strength of sapphire crystals was measured using 4-points method as it described in [18]. Specimens with dimensions $3.5 \times 5 \times 50 \mathrm{~mm}$ were oriented according to three $(\mathrm{C}, \mathrm{A}$ and $\mathrm{M})$ crystallographic axes of sapphire crystal with accuracy of $+/-0.5$ degree. All specimens were fine ground finished and annealed at $1950^{\circ} \mathrm{C}$ in vacuum for 2 hours in order to reduce stresses produced by mechanical grinding. We used 4-5 samples of each type orientation to measure flexure strength.. 
All samples were cut from crystals grown by Kyropoulos method with Verneuil and EMT HPDA ${ }^{\circledR}$ starting materials. Results are presented in Table 2.

There is correlation between flexure strength and crystallographic orientation in all studied sapphire crystals. Flexure strength has the highest value for the group I (table 2) when $\mathrm{C}$ axes is located along the longest side of the specimens. These data is in a good agreement with the results obtained by [25]. This type of specimens has shown the largest (up to 40\%) enhancements of the flexure strength if crystals are grown using EMT HPDA ${ }^{R}$ starting material. Enhancement in flexure strength up to $24 \%$ have shown by the specimens if $c$ axes is perpendicular to the longest side of the sample ( groups III and IV). The lowest increase in the flexure strength is obtained for the samples when c axes is parallel to the loading force (group II).

Table 2.

Room temperature flexure strength of sapphire crystals grown by Kyropoulos method

\begin{tabular}{|c|c|c|c|}
\hline Type & Sample Orientation & $\begin{array}{l}\text { Flexure Strength (MPa) } \\
\text { (Starting Material) }\end{array}$ & $\begin{array}{l}\text { Flexure Strength } \\
\text { Variation (\%) }\end{array}$ \\
\hline & & $\begin{array}{l}648+/-32\left({ }^{(E M T ~ H P D A}{ }^{\circledR}\right) \\
467+/-15 \text { (Verneuil) }\end{array}$ & $39 \%$ \\
\hline & & $\begin{array}{l}418+/-22\left(\text { EMT HPDA }^{\circledR}\right) \\
370+/-10 \text { (Verneuil) }\end{array}$ & $13 \%$ \\
\hline & & $\begin{array}{l}426+/-38\left({ }^{(E M T ~ H P D A}{ }^{\circledR}\right) \\
343+/-27 \text { (Verneuil) }\end{array}$ & $24 \%$ \\
\hline TV & $\mathrm{m}$ & $\begin{array}{l}390+/-20\left(\text { EMT HPDA }^{\circledR}\right) \\
315+/-20 \text { (Verneuil) }\end{array}$ & $24 \%$ \\
\hline
\end{tabular}

It is well know that hydrogen deteriorates mechanical properties of materials, especially single crystals reducing its strength [19]. Deterioration of mechanical strength of quartz crystals was also observed in [26]. Very small amounts of water in the quartz lattice dramatically affect its mechanical properties. The mechanical strength of "wet" quartz is at least 10 times lower than that of "dry" quartz. This effect of water on quartz has been called hydrolytic weakening [26] The effect of water on mechanical properties of sapphire was reported in [27]. The authors enhanced sapphire samples with water at elevated pressure and temperature and observed sharp (up to $50 \%$ ) reduction in strength of sapphire crystals at elevated temperature. Unfortunately, they used the IR absorption method to determine hydrogen concentration and reported very insignificant change in hydrogen concentration that probably did not correspond to actual concentration of water in sapphire crystals. In any case, this significant change in mechanical properties of the sapphire definitely was attributed to enhanced hydrogen 
concentration.

\section{Conclusion}

Systematic study of optical and mechanical properties of sapphire grown by different methods and utilizing different starting materials was carried out.

It was found that:

Hydrogen concentration in sapphire is much higher than was considered in previous works where only IR methods were applied. The IR transmission method does not reflect real hydrogen concentration in sapphire crystals.

It was shown for the first time that NMR method can be successfully used to determine hydrogen content in sapphire crystals.

It was shown that hydrogen concentration in sapphire crystals grown by Verneuil process and sapphire crystals grown from Verneuil material as starting material is very high (up to thousands $\mathrm{ppm}$ ). The source of high hydrogen concentration is due to the nature of Verneuil process that involves hydrogen in the technology of producing Verneuil crystals. This hydrogen is not evaporating in subsequent crystal growth processes regardless of the method to grow sapphire crystals.

EMT HPDA ${ }^{\circledR}$ starting material and sapphire crystals grown from EMT HPDA ${ }^{\circledR}$ starting material have very low hydrogen concentration when measured by NMR analyses.

Sapphire crystals grown from EMT HPDA ${ }^{\circledR}$ starting material have much better optical and mechanical properties compare to the sapphire crystals grown by the same method but using Verneuil starting material or aluminum oxide.

The only significant difference in impurities concentration in these crystals is hydrogen content which probably is the reason for the difference in the optical and mechanical properties of sapphire crystals.

Further investigation is required to determine the mechanisms of hydrogen effect on optical and mechanical properties of sapphire.

\section{Acknowledgments}

We thank Dr. Alfred B. Sinani, loffe Physical Technical Institute, Russian Academy of Sciences, St. Petersburg, Russia, Dr. Leonid A. Litvinov, Institute for Single Crystals, NANU, Kharkov, Ukraine, Dr. Victor I. Privalov, Institute of General and Inorganic Chemistry, Russian Academy of Sciences (IGIC RAS), Moscow, Russia, Dr. Andrey N. Kharlanov, Moscow State University, Moscow, Russia for help in preparing samples and measurements.

\section{REFERENCES:}

1. E.Dobrovinskaya, L.Lytvynov, V.Pischik. Sapphire and other corundum crystals.2002. Kharkov. p.350.

2. E.Dobrovinskaya, L.Lytvynov, V.Pischik. Encyclopedia of sapphire. 2004. Kharkov. p.500.

3. Kurt Schmid, Scott Cohen- Window of opportunity: large sapphire crystals are increasing in demand for many of today's industrial applications-Ceramic Industry, October 2008

4. Mark Akselrod, Sergei Orlov - Optical single-bit recording and fluorescent readout utilizing aluminum oxide single crystals- US patent number 7,072,275, July 4, 2006

5. Shuji Nakamura, Stephen Pearton, Gerald Fasol- The Blue laser diode: The complete storysecond revised enlarged edition. Springer, 2000

6. Toshiyuki Nakamura, Hideaki Matsuhashi, Yoshiki Nagamoto- Silicon on sapphire (SOS) device technology-OKI Technical Review, issue 200, v.71, N4, pp. 66-69, 2004

7. Christopher D Jones, Jeffrey B. Rioux, John W. Locher, Herbert E. Bates, Steven A. Zanella, Vincent Pluen, Mattias Mandelartz -Large-area sapphire for transparent armor - 
American Ceramic Society bulletin , v.. 85, n3, pp. 24-26, 2006

8. Sapphire Market 2008 ,Research Report \# YD4303 - Yole Development, France, October 2008

9. K. Nassau- "Reconstructed" or "Geneva" Ruby- Journal of Crystal Growth, v.5, issue 5, pp.338-344. 1969

10. Gijbels, A. Bogaerts- Recent trends in Solid mass spectrometry: GDMS and other methods, Presenius J. Anal Chem, v.359, p. 326-330, 1997

11. F.I. King, J. Teng, R.E. Steiner- Glow Discharge Mass Spectrometry: Trace element determination in Solid Samples, Journal of Mass Spectrometry, v.30, p.1061-1075, 1995

12. K Nakamoto - Infrared and Raman Spectra of Inorganic and Coordination Compounds, Part A: Theory and Applications in Inorganic Chemistry, 5th ed. John Wiley \& Sons, Ltd, 1997

13. F.K. Volinets, V.G. Vorob'ev, E.A. Sidorova - Infrared absorption bands in corundum crystalsJournal of applied spectroscopy, v.10, N6, pp.665-667, 1968

14. K. Volinets, E.A. Sidorova, N.A. Stsepuro - OH groups in corundum crystals which were grown with the verneille technique- Journal of applied spectroscopy, v.17, N6, pp.1626-1628, 1972

15. Anton Beran, George R. Rossman- $\mathrm{OH}$ in naturally occurring corundum-European Journal of Mineralogy, v. 18; N4; pp. 441-447, 2006

16. Simon C. Kohn- Structural Studies of $\mathrm{OH}$ in nominally Anhydrous minerals using NMRReviews in Mineralogy and Geochemistry, v.62, N1, pp.53-66, 2006

17. Radion Mogilevsky, Liudmila G. Sharafutdinova, Scott D. Mittl-Optical Properties of SapphireProceeding of SPIE, v.7056, 2008

18. Daniel C. Harris- Infrared window and dome materials-_SPIE Optical Engineering Press, 1992, p.175

19. Ignatius S.T. Tsong, Alex C. Mclaren, Bruce E. Hobbs-Determination in hydrogen in silicates using the ion beam spectrochemical analyzer: application to hydrolytic weakeningAmerican Mineralogist, v.61, pp 921-926, 1976

20. Barry C. Barish, Jordan Camp, William P. Kells, Gary H. Sanders, Stan E. Whitcomb, Liyuan Zhang, Ren-yuan Zhu, Peizhen Deng, Jun Xu, Guoqing Zhou, and Yongzong Zhuo -Development of Large Size Sapphire Crystals for Laser Interferometer Gravitational Wave Observatory- LIGO-P010036-00-D, November, 2001

21. M.E. Innocenzi, R.T. Swimm. M. Bass, R.H. French, A.B. Villaverde, M.R. Kokta- Room Temperature optical absorption in undoped alpha $\mathrm{Al}_{2} \mathrm{O}_{3}$ - J. Appl. Phys. 67-69, 7542,1990

22. R. Mogilevsky, S. Nedilko, L.G. Sharafutdinova, S. Burlay, V. Sherbatski, V. Boyko, S.D. Mittl-Luminescence study of grown sapphire: from starting material to single crystalsPhysica Status Solidi, C, to be published

23. X. Sun, S. Goss, L. Brillson, D. Look, and R. Molnar -Electronic Defect States Observed by Cathodoluminescence Spectroscopy at GaN/Sapphire Interfaces -Phys. Stat. sol. (b), v. 228, pp. 441-444, 2001.

24. A. Escobosa, V. Sánchez, R., M. Avendaño, G.Navarro - Photoluminescence studies of $\mathrm{GaN}$ : A comparison between layers grown on sapphire and nitridated $\mathrm{GaAs}$ layers- Phys. Stat. Sol. (b), v. 242, pp.1883 -1886, 2005

25. F. Schmid, C.Khattak, P.Chandra .;M. Smith, .M., Felt, -.Current status of sapphire for optics- Proc. SPIE Vol. CR67, pp. 137-158, 1997

26. J.C. Doukhan -.Lattice Defects and Mechanical Behaviour of Quartz SiO2- Journal de Physique III, v. 5, issue 11, pp. 1809-1832, 1995

27. J. Castaing, A.K. Kronenberg, S.H. Kirry, T.E. Mitchel-Hydrogen defects in alpha $\mathrm{Al}_{2} \mathrm{O}_{3}$ and water weakening of sapphire and alumina ceramics between 600 an $1000{ }^{\circ} \mathrm{C}$-II. Mechanical properties- Acta Materialia, v.48, pp.1495-1504, 2000 